\title{
Microscopic Surgery with Coblation for the Treatment of Benign Laryngeal Lesions: A Case Report
}

\author{
Anant Chouhan, Mohan Kulhari, B. Amisha, Neeraj Kasliwal \\ Department of ENT, Fortis Hospital, Jaipur, India \\ Email: dr.apschouhan@gmail.com
}

Received 4 March 2016; accepted 10 May 2016; published 13 May 2016

Copyright (C) 2016 by authors and Scientific Research Publishing Inc.

This work is licensed under the Creative Commons Attribution International License (CC BY). http://creativecommons.org/licenses/by/4.0/

c) (i) Open Access

\begin{abstract}
Background: Coblation based bipolar plasma devices are designed to operate at a relatively low temperature to gently dissolve and/or shrink target tissue with minimal thermal damage to surrounding healthy tissue. Coblation technology provides ablation, resection, coagulation of soft tissue and hemostasis of blood vessels in one convenient surgical device. Coblation technology can be used in the larynx and trachea for removing or debulking sessile polyps, lesions or tumors. Minimally invasive coblation technology can offer less invasive treatment with quicker recovery and shorter hospitalization. Aim: This case study aims to explore the advantages of coblation combined with microscopy to treat benign laryngeal lesions. Case report: We report the case of laryngeal papilloma treated with minimally invasive coblation resection. Fiberoptic laryngoscopy was done pre-operatively and that showed papillomatous mass at anterior half of right vocal cord involving inferior surface and also extending upto anterior commissure. Mobility of both vocal cords was normal. On the basis of the above findings with normal vocal cords mobility, the microlaryngeal surgery with coblation was planned. After complete pre-op work up, the patient underwent trans-oral microscopic coblation excision of mass under general anaesthesia. Power level was set to 7 for ablation and 3 for coagulation. The PROcise ${ }^{\text {TM }}$ LW Plasma Wand system was chosen such that it was malleable to reach the papillomatous mass without obstructing the vision. It was totally excised and sent for histopathology examination. Post-operatively after four hours, he was able to take normal diet comfortably. He was followed up after 10 days. Histopathological report confirmed the diagnosis of papilloma. Check laryngoscopy was performed after 3 weeks. Laryngeal examination was absolutely normal with almost normal vocal cords and normal voice post- operatively. Conclusion: Microscopic surgery with coblation has the advantages of less bleeding, short procedure duration, increased completion rate and few complications.
\end{abstract}

\section{Keywords}

Hoarseness, Papilloma Larynx, Coblation, Microlaryngeal Surgery

How to cite this paper: Chouhan, A., Kulhari, M., Amisha, B. and Kasliwal, N. (2016) Microscopic Surgery with Coblation for the Treatment of Benign Laryngeal Lesions: A Case Report. International Journal of Otolaryngology and Head \& Neck Surgery, 5, 125-128. http://dx.doi.org/10.4236/ijohns.2016.53021 


\section{Introduction}

Benign neoplasms of the larynx constitute an interesting array of lesions that produces symptoms which can vary from mild hoarseness to life threatening stridor. These lesions can create a lot of mental and emotional tension in the patient and the family [1]. Adult recurrent respiratory papillomatosis peaks between the ages of 20 and 40 years and has a slight male prediction. The hoarseness is the most constant, and prominent presenting features in the present study which is in accordance with other various studies [2].

In the last few years, different techniques have been proposed to reduce morbidity and surgical risk. Surgeons must lay particular attention to the safety, accuracy and outcomes when choosing among different surgical techniques [3].

Coblation technology can be used in the larynx and trachea for removing or debulking sessile polyps, lesions or tumors. Coblation based bipolar plasma devices are designed to operate at a relatively low temperature to gently dissolve and/or shrink target tissue with minimal thermal damage to surrounding healthy tissue. Coblation technology provides ablation, resection, coagulation of soft tissue and hemostasis of blood vessels in one convenient surgical device [4]-[6]. The PROcise ${ }^{\mathrm{TM}}$ LW Plasma Wand is designed for controlled removal of bulky, and sessile laryngeal lesions. It provides ablation, coagulation, irrigation, and suction capabilities in one versatile single-use device [6].

Objective: This case study aims to explore the advantages of coblation combined with microscopy to treat benign laryngeal lesions

\section{Case Report}

A 35 years old male presented with change in voice since 5 months. Fiberoptic laryngoscopy was done and that showed papillomatous mass at anterior half of right vocal cord involving inferior surface and also extending upto anterior commissure. Mobility of both vocal cords was normal (Figure 1). He had already visited other centers and they suspected the lesion as malignant and advised biopsy as the complete excision of lesion is difficult with routine microlaryngeal instruments or laser.

On the basis of the above findings with normal vocal cords mobility the microlaryngeal surgery with coblation was planned. After complete pre-op work up, the patient underwent trans-oral microscopic coblation excision of mass under General Anaesthesia.

After the General Anaesthesia was given, the patient was put in Boyce position and a Klein Sauccer suspension laryngoscope was introduced. Operating microscope using a $400 \mathrm{~mm}$ objective lens was utilised for visualising the mass. Power level was set to 7 for ablation and 3 for coagulation. The PROcise ${ }^{\mathrm{TM}}$ LW Plasma Wand system was chosen such that it was malleable to reach the papillomatous mass without obstructing the vision. The mass was held with cupped forceps at its medial end and foot pedal ablation was activated when the wand was close to the lateral edge of the mass, avoiding direct contact. Dissection was carried out deeply and the lesion was then drawn towards the midline and cut off at its base with coblator. In this way, a strip of mucosa was not removed unnecessarily along with the lesion. It was totally excised and sent for histopathology examination. The wand was carefully inserted and removed in the laryngoscope without touching its wall and avoiding injury to laryngeal structures. Microscopic check of whole area was performed to ensure complete removal of mass with the help of retractor. The absence of any bleeding or mucosal damage was verified. Then patient was extubated and shifted safely.

Post-operatively after four hours he was able to take normal diet comfortably without any complaints of pain, bleeding and vomiting. He was discharged on next day with medications and advice of absolute voice rest.

He was followed up after 10 days. He has no complaints and biopsy confirmed the clinical diagnosis of papilloma. He was then allowed gradual resumption of voice. Check laryngoscopy was performed after 3 weeks. Laryngeal examination was absolutely normal with almost normal vocal cords and normal voice postoperatively (Figure 2).

\section{Discussion}

Minimally invasive coblation technology can offer less invasive treatment with quicker recovery and shorter hospitalization. The characteristic procedures involve exposing the larynx with a laryngoscope and using low temperature plasma technology to visualize the tumor resection, as the effects of plasma technology can reduce 


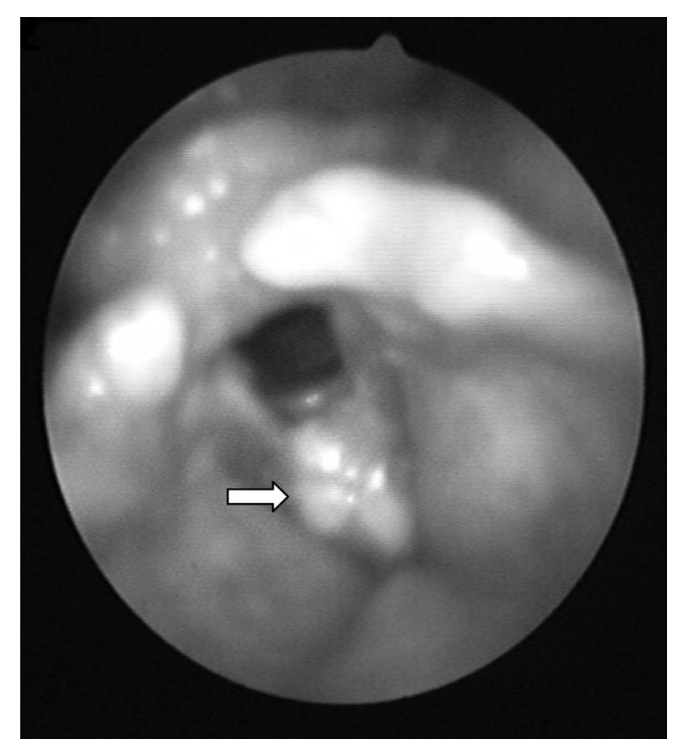

Figure 1. Papillomatous mass at anterior half of right vocal cord involving inferior surface and also extending upto anterior commissure (arrow).

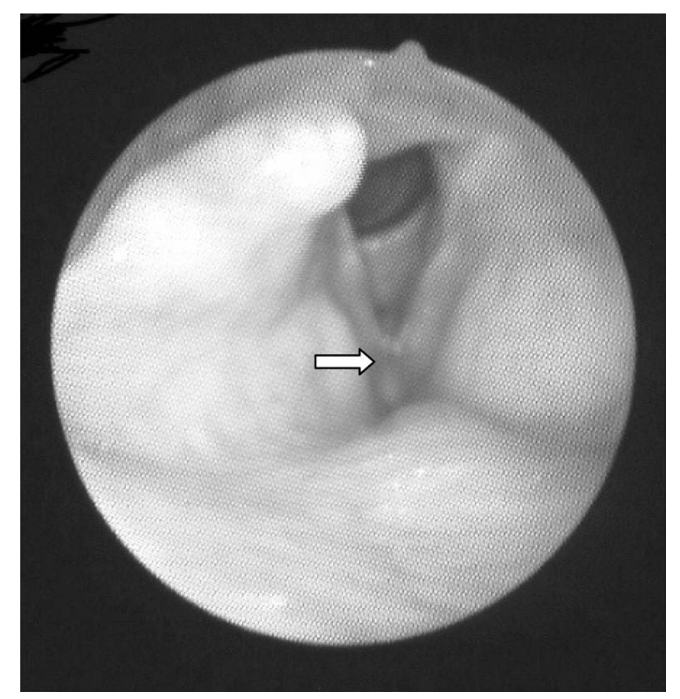

Figure 2. Laryngeal examination after 3 weeks was absolutely normal with almost normal vocal cords (arrow).

post-operative laryngeal edema and reduce intraoperative metastasis [7].

Microlaryngeal surgery with coblation is better than the use of conventional microlaryngeal instruments that have limited approach and lasers which require a large number of personnel to ensure effectiveness and safety. Laser is more costly and its heat can increase scarring and damage to adjacent tissue. Other limitations of laser include potential for endotracheal explosion thus needs special tubes for anaesthesia, mucosal burns, vocal fold webs, stenosis and glottic incompetence [8] [9]. Under normal operating circumstances, using coblation technology in place of traditional electrosurgical or laser devices can significantly reduce the risk of igniting an airway fire [4]-[6].

PROcise $^{\mathrm{TM}}$ LW Plasma Wand used in coblation technique has excellent features. These include:

[a] Enhanced flat-screen active electrode configuration that enables efficient bipolar ablation and coagulation during laryngeal surgical procedures.

[b] Long, low-profile malleable Wand shaft allows increased surgical field visualization, adjustable to individual anatomy and access to the anterior commissure of the larynx.

[c] Unique integrated saline irrigation and suction capabilities so that optimum saline delivery to active elec- 
trode made possible regardless of Wand orientation [6].

Microscopic surgery with coblation in this patient allowed complete removal of lesion in short duration with precision that would be difficult with other techniques as the papillomatous mass extended upto the undersurface of vocal cord and involving anterior commissure which was not easily approachable without damaging adjacent tissues. This was similar to the observation made by a different study [10].

\section{Conclusion}

The present study demonstrated that application of coblation in laryngeal surgery significantly increased completion rate of surgery, a bloodless field, avoiding collateral tissue damage and reduced operation time. Thus, microscopic surgery with coblation is worthy of clinical application.

\section{Conflict of Interest}

None.

\section{References}

[1] Singhal, P., Bhandari, A., Chouhan, M., Sharma, M.P. and Sharma, S. (2009) Benign Tumors of Larynx. Indian Journal of Otolaryngology and Head and Neck Surgery, 61, 26-30. http://dx.doi.org/10.1007/s12070-009-0013-9

[2] Hedge, M.C., Kamath, M.P., Bhojwani, K., Peter, R. and Babu, P.R. (2005) Benign Lesions of the Larynx-A Clinical Study. Indian Journal of Otolaryngology and Head and Neck Surgery, 57, 35-38.

[3] Songu, M., Altay, C., Adibelli, Z.H. and Adibelli, H. (2010) Endoscopic Assisted versus Curettage Adenoidectomy: A Prospective, Randomized, Double Blind Study with Objective Outcome Measures. Laryngoscope, 120, 1895-1899. http://dx.doi.org/10.1002/lary.21045

[4] Smith, L.P. and Roy, S. (2011) Operating Room Fires in Otolaryngology: Risk Factors and Prevention. American Journal of Otolaryngology, 32, 109-114.

[5] Roy, S. and Smith, L.P. (2010) Device-Related Risk of Fire in Oropharyngeal Surgery: A Mechanical Model. American Journal of Otolaryngology, 31, 356-359. http://dx.doi.org/10.1016/j.amjoto.2009.05.006

[6] Matt, B.H. and Cottee, L.A. (2010) Reducing Risk of Fire in the Operating Room Using Coblation Technology. Otolaryngology—Head \& Neck Surgery, 143, 454-455. http://dx.doi.org/10.1016/j.otohns.2010.05.013

[7] Zhou, C.Y., Sun, B.C., Wang, F., et al. (2014) Coblation plus Photodynamic Therapy (PDT) for the Treatment of Juvenile Onset Laryngeal Papillomatosis: Case Reports. World Journal of Surgical Oncology, 12, 275. http://dx.doi.org/10.1186/1477-7819-12-275

[8] Zeitels, S.M. and Burns, J.A. (2006) Laser Applications in Laryngology: Past, Present, and Future. Otolaryngologic Clinics of North America, 39, 159-172. http://dx.doi.org/10.1016/j.otc.2005.10.001

[9] Yan, Y., et al. (2010) Use of Lasers in Laryngeal Surgery. Journal of Voice, 24, 102-109. http://dx.doi.org/10.1016/j.jvoice.2008.09.006

[10] Rachmanidou, A. and Modayil, P.C. (2011) Coblation Resection of Paediatric Laryngeal Papilloma. Journal of Laryngology and Otology, 125, 873-876. http://dx.doi.org/10.1017/S0022215111001253 